\title{
Vorwort zur zweiten, überarbeiteten Auflage
}

Mit seiner Edition der Exzerpte aus dem Kirchengeschichtswerk des Philostorgios hatte Joseph Bidez ein Meisterwerk vorgelegt. Darin waren sich bei ihrem Erscheinen vor über einem halben Jahrhundert alle Rezensenten einig. Auch heute noch ist die Ausgabe mustergültig und kann lediglich an einigen Stellen (vor allem auf hagiographischem Gebiet) ergänzt oder verbessert werden. So könnte der Unterzeichnete mit gutem Gewissen dem Drängen des Verlages nachgeben, eine überarbeitete Auflage zu besorgen, die sich auf die Zusammenstellung von Änderungen und Zusätzen in einem Nachtrag beschränkt und den Text von Bidez unangetastet läßt. (Im Text wird auf solche Nachträge durch ein Sternchen am Rand verwiesen.) Unter die Nachträge wurde auch der Aufsatz aufgenommen, den Bidez in Byzantion 10 (1935) veröffentlichte.

Ein kurzer Wegweiser durch das Werk scheint nicht unangebracht zu sein:

Die von Photios, Niketas Choniates, den Verfassern der Suda und der hagiographischen Texte BHG Nr. 170 (Artemios) und 365 (Konstantin) überlieferten Exzerpte aus dem Werk des Philostorgios, die nach Bidez (S. CXLVf) alle auf das gleiche Exemplar zurückgehen, bespricht Bidez auf den S. XII-XCIX eingehend und bringt sie S. 4 bis 150 zum Abdruck. (S. CLXVIIf Verzeichnis der in der Praefatio besprochenen Textstellen).

Auf den Text folgen sieben Anhänge, die in unterschiedlicher Beziehung zum Philostorgiostext stehen:

Die Anhänge I-III sind den verschiedenen Redaktionen der Passio Artemii gewidmet. Anhang I (S. 151-157. Dazu als Erläuterung S. XLIV ff) bringt die §§ 1-6. 8. 16-18 von BHG Nr. 170 zum Abdruck, die nicht Text des Philostorgios enthalten, in denen der Hagiograph das Werk des Philostorgios charakterisiert. Anhang II (S. 158-165. Dazu als Erläuterung S. LI) ediert die $\S \S 26-29$. 34. 41 f. $46 \mathrm{f}$ aus der gleichen Passio, Teile, die höchstens in kleinen Stücken Text des Philostorgios enthalten. Anhang III (S. 166-175. Dazu als Erläuterung S. XLV-LI. 
LXVIII. CLIX-CLXII) ediert vollständig die vormetaphrastische Passio Artemii (BHG Nr. 196y und z), die zu Philostorgios keine Beziehung hat, die aber neben dem Werk des Philostorgios Quelle des Autors der Passio BHG Nr. 170 war.

Anhang IV (S. 177. Dazu als Erläuterung S. LIf) ediert den Anfang der Vita BHG Nr. 1743 (Theodoros). Zwar behauptet der Hagiograph, das Werk des Philostorgios benutzt zu haben, doch hält das Bidez für unmöglich.

Anhang V (S. 178-183. Dazu als Erläuterung S. XCV-XCVI) ediert ein Stück aus der Vita BHG Nr. 365 (Konstantin), dessen Quelle nicht genau zu bestimmen ist, das aber in Wortschatz und Stil Charakteristika des Philostorgios bietet.

Anhang VI (S. 184-201. Dazu als Erläuterung S. CXLVII-CLI) ediert einige der Passiones des Lukian von Antiochien, die auf die gleiche Quelle zurückgehen, die auch Philostorgios benutzte.

Anhang VII (S. 202-241. Dazu als Erläuterung S. CLI-CLXIII) rekonstruiert eine arianische Fortsetzung der Chronik des Euseb aus dem 4. Jh., die zu den Quellen des Philostorgios gehörte.

Für die Vermittlung von Mikrofilmen der von mir geprüften Handschriften danke ich Herrn Prof. Dr. Marcel Richard. 